\title{
CONCURRENT VALIDITY OF TWO-DIMENSIONAL VIDEO ANALYSIS OF LOWER- EXTREMITY FRONTAL PLANE OF MOVEMENT DURING MULTIDIRECTIONAL SINGLE-LEG LANDING
}

\author{
ABSTRACT
}

Objectives: Establish the concurrent validity between 2D video analysis and 3D motion analysis of frontal plane lower limb movements during multidirectional landing tasks.

Design: Correlation study

Setting: University Biomechanics laboratory

Participants: 34 (19 male, 15 female) uninjured physical active individuals

Main outcome measures: knee abduction and hip adduction angles during a variety of single leg landing tasks.

Results: 2D knee abduction showed an association with 3D knee abduction angle ranging from $r=0.17-0.42$ across the tasks, with $r^{2}$ values ranging between 0.03-0.17. 2D hip adduction angle in both legs reported a strong and significant correlation with 3D hip adduction angle, ranging from $r=0.70-0.90$ across all tasks. Linear regression analysis $\left(r^{2}\right)$ revealed that $49-81 \%$ of 3D hip adduction angle can be explained by $2 D$ measurement.

Conclusion: It might be difficult to explain 3D knee abduction angle using 2D video analysis during single leg landing tasks, whereas 2D hip adduction angle is a strong predictor or 3D hip adduction angle. It would appear 2D video analysis has strong concurrent validity when assessing hip adduction angle, but it is weak when assessing knee abduction angle during a variety of single leg landing tasks.

Keywords: Assessment; kinematics; landing 


\section{HIGHLIGHTS}

- 2D video measured hip adduction angle has strong concurrent validity with equivalent measures from 3D motion analysis during single leg landing tasks.

- 2D video measured knee abduction angle has relatively poor concurrent validity with equivalent measures from 3D motion analysis during single leg landing tasks.

- When using 2D video analysis for screening for injury risk the validity of findings would appear to be task and joint specific 


\section{CONCURRENT VALIDITY OF TWO-DIMENSIONAL VIDEO ANALYSIS OF LOWER- EXTREMITY FRONTAL PLANE OF MOVEMENT DURING MULTIDIRECTIONAL SINGLE-LEG LANDING}

\section{INTRODUCTION}

The ability to screen injury-risk factors can play a key role in the prevention of sport injuries as it helps in identifying modifiable risk factors (McLean et al., 2005) which occur during high risk tasks. Some studies have shown reduced $A C L$ injury incidence through screening individuals with high-risk lower-extremity biomechanics, then undertaking appropriate training to mitigate the risk (Myer et al., 2005).

The gold standard for movement-screening is three-dimensional (3D) motion analysis (McLean et al., 2005), as it provides accurate and reliable 3D lower-extremity measurements while performing different sport tasks (Alenezi et al. 2014; McLean et al. 2004) and contributes effectively to screening and the rehabilitation of injuries related to these tasks. In the study of Alenezi et al, (2014) within day reliability was ICC 0.94 (0.69.96) with a standard error of measurement of 1.4 degrees. It can also accurately describe both multiplane joint angles and moments during functional tasks. However, its application in a clinical setting or to a larger population groups is limited due to the high financial cost and the time-consuming nature of data collection and analysis (Willson \& Davis, 2008; McLean et al. 2005). This suggests a need for simpler and clinically applicable alternatives. Two-dimensional (2D) video analysis has become popular in clinical practice. It only requires a digital video camera and digitizing software. Stensrud et al. (2011) have reported that $2 \mathrm{D}$ motion analysis is universally available, reasonably cheap and typically portable. 2D motion analysis has been used to evaluate lower-extremity kinematics in healthy and injured populations (Herrington \& Munro, 2010; Stenstrud et al., 2011; Herrington, 2011; Willson \& Davis, 2008). However, it is not without its flaws. For instance, it has questionable ability to capture complex and multiplanar dynamic movements. Such a limitation led many studies to question and examine the validity of $2 \mathrm{D}$ motion analysis 
during functional tasks (Mizner et al., 2012; Norris \& Olson, 2011; Olson et al., 2011; McLean et al., 2005; Willson \& Davis, 2008).

The findings of the afore-mentioned studies are conflicting with the correlation between 2D and 3D measurements ranging from 0.15 to 0.77 . Discrepancies in findings may be due to 2D measurement methods and the tasks examined (Nagano., et al., 2008). Jones et al. (2014) attributed these conflicting findings, leading to differences between 2D and $3 D$ motion analysis, to the fact that, in $2 D$, knee flexion can appear as a relatively knee abducted position, particularly when the hip is internally rotated. This suggests that 2D validity, particularly in clinical use, is still unclear and needs more investigation. Moreover, most of the studies examined bilateral tasks and primarily concentrated on the sagittal plane. Bilateral tasks are less challenging to the individual and may mask some important events that can occur during a single leg landing (SLL) which may more closely match the landings occurring in sports. Similarly, the limited research on other than sagittal plane landings may limit understanding of risk of injury, as most sporting activities occur across multiple planes of movement.

Excessive movement within the frontal plane is regarded as important because it is considered a risk factor of knee injury and associated with non-contact ACL injury and patellofemoral joint pain, particularly knee abduction and hip adduction (HADD) (Paterno et al., 2010; Willson et al. 2008). Knee abduction collapse has been identified as a significant position for knee injury during dynamic movement (Krosshaug et al., 2007) and knee abduction and knee abduction loads have been shown to be associated with ACL injuries (Paterno et al., 2010; Shin et al., 2011). Increased load within the frontal plane has been found to increase ACL tension, thus increasing the risk of injury (Shultz et al., 2007).

As the majority of $A C L$ injuries occur during movements in planes of movement other than the sagittal one (Koga et al 2010; Krosshaug et al 2007) having an understanding of landing kinematics in the sagittal plane alone, may not provide sufficient insight to understand the underpinning mechanisms involved in the faulty movement mechanics 
related to injury. In their recent review Davies et al., (2019) concluded the inclusion of multiple plane landing would give greater information about knee performance. In advance of assessing landings across multiple planes to assess outcome from rehabilitation or for screening of injury risk it would be expedient to assess the validity of the tools which will be potentially used to undertake these measurements. Hence a battery of different single leg landing tasks will be used in this study.

To the best of the researcher's knowledge, no study has examined both hip and knee frontal-plane kinematics during a battery of single-leg tasks. Consequently, the aim of this study was to examine the validity of 2D video analysis against the assumed gold-standard 3D motion analysis when examining lower-extremity frontal-plane kinematics variables (frontal plane projection angle (FPPA), knee abduction angle and HADD angle) during multidirectional single leg landing tasks. With the study hypothesis being FPPA and HADD angles measured using 2D video will be strongly correlated to the corresponding measurements (knee abduction and HADD angles) acquired with 3D motion capture.

\section{METHOD}

\section{Participants}

The demographics of participants in the study are shown in table 1. All participants had no lower limb injuries or surgery and were physically active participating in at least 3 hours of physical activity per week. The study was approved by the university research committee and all participants gave written informed consent to participate.

\section{Procedures}

\section{Tasks}

The procedures for the landing tasks undertaken are described in table 2. All participants carried out the tasks in a random order, completing 3 successful trials from a maximum 
of 5 trials for each task. Participants had 1-minute recovery between trials and 3 minutes recovery between each task.

\section{D video analysis}

The method replicates the one with previously reported reliability (Munro et al., 2012) with one digital video camera (Casio EX-F1, Japan) sampling at $30 \mathrm{~Hz}$ being used to videotape subjects when performing the tasks (Table 2), it was positioned on a tripod at a horizontal distance of $2 \mathrm{~m}$, a height of $0.8 \mathrm{~m}$ in front of the force platform, perpendicular to the frontal plane of motion. The data collected during the multidirectional SLLs for each participant were transferred from the camera to a computer. The 2D kinematic data were analysed using Quintic Biomechanics Software (v21, Quintic, Sutton Coldfield, UK) by a single rater (AAM). To determine FPPA, each SLL trial was reviewed, until peak FPPA was considered to have been observed this value was then recorded. Using the angle tool of the software, a line was drawn from the centre of ASIS to the centre of the marker placed on the midpoint of the knee joint. Another line was drawn from the latter marker to the marker placed on the midpoint of the ankle mortise. The angle between these lines was defined as FPPA. A negative value represents knee abduction, which means the marker on the mid-joint of the knee moves towards the midline of the body, while a positive value represents knee adduction, which means the marker on the mid-joint of the knee moves outside the midline of the body. To calculate the right HADD angle, a line was drawn from the left ASIS to right ASIS, and another line from right ASIS to the marker on the midpoint of the right knee joint. To calculate the left HADD angle, a line was drawn from right ASIS to left ASIS, and another line from left ASIS to the marker on the midpoint of the left knee joint. Notionally the 90-degree alignment between the ASIS line and the femoral line was used as the zero-degree position and a positive value means HADD and a negative value means hip abduction. To determine HADD angle, each SLL trial was reviewed, until peak HADD was considered to have been observed, this value was then recorded. The All 2D trials were of the same trials that were accepted for 3D analysis, but concurrently captured by a $2 \mathrm{D}$ digital camera 


\section{D motion capture}

The method replicates the one with previously reported reliability (Alenezi et al., 2014) with a 10-camera motion analysis system (Pro-Reflex, Qualisys, Sweden), sampling at $240 \mathrm{~Hz}$, and a force platform embedded into the floor (AMTI, USA), sampling at $1200 \mathrm{~Hz}$, were used to collect the kinematic and kinetic variables during the support phase of the landing tasks. Before testing, subjects were fitted with standard training shoes (New balance, UK). Reflective markers $(14 \mathrm{~mm})$ were attached with self-adhesive tape to the participants lower extremities over the following landmarks: anterior superior iliac spine, posterior superior iliac spines, mid-point of iliac crest, greater trochanters, medial and lateral femoral condyles, medial and lateral malleoli, posterior calcanei, and the head of the $1^{\text {st }}, 2^{\text {nd }}$ and $5^{\text {th }}$ metatarsal by a single researcher $(A A M)$. The tracking markers were mounted on technical clusters on the thigh and the shank with elastic bands. The same individual placed the markers on all participants. The calibration anatomical system technique (CAST) was employed to determine the 6 degrees of freedom of movement of each segment and anatomical significance during movement trials. The static trial position was designated as the participant's neutral (anatomical zero) alignment, and subsequent kinematic measures were related back to this position.

Visual 3D motion (Version 4.21, C-Motion Inc, USA) was used to calculate the joint kinematic data. Motion and force plate data were filtered using a Butterworth $4^{\text {th }}$ order bidirectional low pass filter with cut off frequencies of $12 \mathrm{~Hz}$. All lower extremity segments were modelled as conical frustra, with inertial parameters estimated from anthropometric data. Kinematic data were normalised to the right leg descend phase during landing. Joint kinematic data was calculated using an X_Y_Z Euler rotation sequence. The peak angles for knee abduction and HADD were record from each successful trail and compared to the corresponding FPPA and HADD angles extracted from the 2D video.

\section{Statistical analysis}


The data were analysed using IBM SPSS Statistics 21 (IBM Corp, Armonk, NY, USA). The variables examined in a validity study were tested for normality using a Shapiro Wilk's test and met all other assumptions to undertake parametric statistical analysis. The association of 2D variables (FPPA and HADD) with corresponding 3D variables (knee-valgus angle and HADD angle) was examined in both legs using Pearson's product-moment correlation ( $r$ ). The classification of strength of correlation is small $(0-0.3)$, moderate $(0.3-0.5)$, strong $(0.5-0.7)$ and very strong (0.7- 1$)$, with statistical significance set at an alpha level of 0.05, as described by Hopkins, et al., 2009. To evaluate how a 2D variable can explain and account for the variability of corresponding 3D variables, a linear regression analysis $\left(r^{2}\right)$ was performed using 2D variables as independent (predictor) variables and 3D variables as dependent (predicted) variables.

\section{RESULTS}

In table 3 are the means $( \pm S D$ ) for $2 D$ and $3 D$ variables in all tasks.

Table 4 shows Pearson correlation ( $r$ ) ( $P$ value) and linear-regression analysis $\left(r^{2}\right)$ results for 2D variables (FPPA and HADD angle) with corresponding 3D variables (knee valgus and HADD angle) for both legs during all tasks.

2D FPPA showed an association with 3D knee-valgus angle ranging from $r=0.17-0.42$, with the majority also not being statistically significant. The largest correlation (moderate) was noted between these variables in FSLL, LSLL and MSLL (Table 4), but these were only statistically significant for the left leg. The smallest correlation $(r=0.17)$ was reported for the left leg during FSLLP and for the right leg during LSLLP. Linear regression analysis reported $r^{2}$ values ranging between $0.03-0.17$ for the right leg and between $0.03-0.16$ for the left leg, indicating that 2D FPPA might be, at best, a moderate predictor, as it can explain up to $17 \%$ of 3D knee abduction angle but only for tasks performed without a step.

2D HADD angle in both legs reported a strong and significant correlation with 3D HADD angle, ranging from $r=0.70-0.90$ in all tasks. Linear regression analysis $\left(r^{2}\right)$ revealed that $49-81 \%$ of 3D HADD angle can be explained by 2D measurement (Table 4 ). 


\section{DISCUSSION}

The current study was conducted to increase the knowledge about video-based motion analysis by examining the validity and correlation between 2D and 3D lower-extremity frontal plane movements during multidirectional SLL. To the best of the researcher's knowledge, this is the first study to examine such a relationship during this variety of tasks. Other tasks have been examined such as drop vertical jump (Belyea et al., 2015; Ortiz et al., 2016) and single-leg drop jump (Sorenson et al., 2015). Most of the previous literature has only assessed 2D FPPA to quantify 3D knee-valgus angle and only examined one leg (dominant) (Sigward et al., 2008; McLean et al., 2005). The current study examined 2D FPPA and HADD angle to quantify the corresponding 3D variables in both legs, which may help practitioners to accurately compare between legs.

The findings of the present study failed to support the first hypothesis, as they indicate that 2D FPPA, at best, moderately correlates with 3D knee-valgus angle during forward, lateral and medial SLL (table 4), and often without statistical significance. Linear regression analysis indicates that 2D FPPA can, at best, explain up to $17 \%$ of 3D kneevalgus angle, but only for tasks performed when not jumping off a step. So, the FPPA angle generated from 2D video does not represent the knee abduction angle generated from 3D analysis during landing tasks.

Such findings are comparable with some of the literature, but not all. Slightly better correlations between 2D knee FPPA and 3D knee valgus were found during side step $\left(r^{2}=\right.$ $0.25)$, side jump $\left(r^{2}=0.36\right)$ (McLean et al., 2005), single leg squat $\left(r^{2}=0.31\right)$ (Schurr et al., 2017) and 5-repetition vertical jump ( $\left.r^{2}=0.34\right)$ (Nagano et al., 2008) tasks. The slightly better results might be due to several reasons. First, there are differences between the method used in the current study and in McLean et al's. (2005) study. The joint centres in the current study were determined using retroreflective markers during data collection, while they were determined manually during the digitisation process in McLean et al.'s (2005) study. Manual estimation of joint centres has been shown to be less reliable, which may have introduced bias into McLean et al.'s (2005) study. Secondly, the populations 
examined where McLean et al. (2005) examined basketball players with playing experience of more than ten years. It is well known that this sport is very demanding and involves many single-leg manoeuvres, which means that the participants may have adapted to perform the task better than those in the current study, and potentially in a more consistent manner.

Like the present study, Willson and Davis (2008) examined the utility of 2D FPPA, they did so in female subjects with and without patellofemoral pain (PFP). They found that 2D FPPA did not significantly correlate with 3D knee-valgus angle during single leg squat $(r=0.21)$. Such results may contextualise the current study's findings, as they examined fewer dynamic tasks which can be performed with more stability than those examined in the present study. Sorenson et al. (2015) reported a correlation between 2D FPPA and 3D knee valgus during single-leg drop landing, which was less than that reported in the current study $\left(r^{2}=0.06\right)$. This correlation increased to $\left(r^{2}=0.72\right)$ when examined at initial ground contact, where the leg is in a more extended position, which may minimise out-of-plane error, while the measurements in the current study were taken with the knee in flexion. Out-of-plane error was found to increase when knee flexion exceeded $40^{\circ}$ (Cheng \& Pearcy 1999).

Belyea et al. (2015) examined the correlation between 2D FPPA and 3D knee-valgus angle at maximum knee flexion during drop vertical jump and a significant correlation was reported $(r=0.48)$. A handheld tablet to capture 2D video was used in Belyea et al.'s (2015) study. This may have affected the orientation of the tablet when collecting the data and affected the angle of the tablet relative to the plane of movement, which may result in parallax error, which, in turn, could affect the results. Parallax error can occur when the subject is viewed away from the optical axis of the camera (Kirtley, 2006). Also, the between-subject variability might be less than it is in the current study, as they examined double-leg tasks which give additional support and stability.

The findings regarding the validity of 2D FPPA against 3D knee valgus are conflicting and might be inversely correlated with the difficulty of the task. For instance, when performing 
a double-leg task, the two legs provide more base support and more stability than a oneleg task, which is expected to offer better measurement for the frontal plane of movement. In the current study, it was observed that the participants struggled to quickly stabilise the lower limb when SLL, which resulted in movement of the knee from side to side. This may have led to the variables being collected at different times during the landing cycle. Such an observation may explain why other studies found a good correlation at IC (Sorenson et al., 2015), as measurements were taken with the knee nearly extended and before subjects started struggling with their balance. However, the occurrence of injury was suggested to be in a position of no return, which includes knee flexion, so measurements should be taken in a knee-flexion position for greater external validity. In the current study, there were differences in data-collection frame rates between 2D (sampled at $30 \mathrm{~Hz}$ ) compared to the faster 3D sampling frame $(240 \mathrm{~Hz})$. This may have led to asynchronistic timing of data capture. Such limitations may explain the lack of significant correlation between 2D FPPA and 3D knee valgus (Maykut et al., 2015). Greater correlation may be gained with a higher 2D sampling rate.

FPPA is not a single movement but rather a combination of movements, which includes rotation. 2D measures movement in a constant line of the frontal plane, which does not consider rotational movement. This may also affect the ability of 2D FPPA to predict 3D knee valgus. 2D FPPA measurements also overestimated values, compared to 3D. A possible explanation is the influence of sagittal-plane movement, as knee flexion can appear as knee abduction when the hip is internally rotated (Jones et al., 2014). This could have influenced our findings. Also, the correlation between time to balance and frontalplane biomechanics was not measured in the present study, but it needs to be considered in future studies.

This study also examined the validity of 2D HADD angle compared to 3D HADD angle. 2D HADD angle in both legs had a strong positive correlation with 3D HADD angle, ranging between $r=0.70-0.90$ in all tasks (table 4 ). Linear regression analysis $\left(r^{2}\right)$ revealed that 49-81 per cent of 3D HADD angle can be explained by 2D measurement (Table 3), which 
means that 2D HADD angle is a good predictor of 3D HADD angle. This suggests that 2D motion analysis may be an applicable surrogate for 3D motion analysis for hip adduction during landing.

Most of the studies that have examined the relationship between 2D, and 3D frontal-plane biomechanics focused only on the knee. Only one study has examined the relationship between 2D and 3D hip kinematics during landing. Sorenson et al. (2015) reported a similar correlation between 2D HADD angle and 3D HADD angle at initial foot contact during single-leg drop jump $(r=0.72)$ with $52 \%$ of the variability of $2 \mathrm{D}$ HADD being explained by the variability in 3D HADD $\left(r^{2}=0.52\right)$. This correlation increased to $r=0.84$, with almost $70 \%$ of the 2D hip FPPA being explained by the variability in the 3D hip frontal plane position at maximum excursion. However, only female participants and one direction of landing were examined in the study by Sorenson et al. (2015).

The results of the current study are important. Studies that examined the validity of 2D motion analysis compared to 3D mainly focused on FPPA, and only during limited tasks. HADD has been suggested as being associated with knee injury and the current study suggests that $2 \mathrm{D}$ motion analysis can be a valid alternative to $3 \mathrm{D}$ when measuring HADD angle during single-leg tasks, such as those included in the current study. Some clinical advantages might be gained from simple 2D motion analysis during multidirectional SLL. Compared to 3D, using 2D can help the practitioner to screen and identify those who are at elevated risk of knee injury related to increased HADD.

\section{CONCLUSION}

This study forms part of an increasing body of evidence exploring the relationship between 2D and 3D motion analysis for measuring knee and hip angles. The results of this study suggest that $2 \mathrm{D}$ motion analysis might be an applicable alternative method when measuring knee and hip angles, particularly in the field or in a clinic which do not have access to a 3D motion system. However, caution should be taken when using 2D analysis 
to predict 3D knee abduction angles, as it shows low validity. Nevertheless, the clinical utility of such findings needs to be examined. 


\section{REFERENCES}

Alenezi, F., Herrington, L., Jones, P., \& Jones, R. (2014). The reliability of biomechanical variables collected during single leg squat and landing tasks. Journal of Electromyography and Kinesiology, 24(5), 718-721

Belyea, B., Lewis, E., Gabor, Z., Jackson, J., \& King, D. (2015). Validity and Intra-rater Reliability of 2-Dimensional Motion Analysis Using a Hand-held Tablet Compared to Traditional 3Dimensional Motion Analysis. Journal of Sport Rehabilitation, dx.doi.org/10.1123/jsr.2014-0194

Cheng, P., \& Pearcy, M. (1999). A three-dimensional definition for the flexion/extension and abduction/adduction angles. Medical \& Biological Engineering \& Computing, 37(4), $440-444$

Herrington, L., \& Munro, A. (2010). Drop jump landing knee valgus angle; normative data in a physically active population. Physical Therapy in Sport, 11(2), 56-59.

Herrington, L. (2011). Knee valgus angle during landing tasks in female volleyball and basketball players. The Journal of Strength \& Conditioning Research, 25(1), 262-266

Hopkins, W., Marshall, S., Batterham, A., \& Hanin, J. (2009). Progressive statistics for studies in sports medicine and exercise science. Medicine and Science in Sports and Exercise, 41(1), 3-12

Jones, P., Herrington, L., Munro, A., \& Graham-Smith, P. (2014). Is there a relationship between landing, cutting, and pivoting tasks in terms of the characteristics of dynamic valgus? American Journal of Sports Medicine, 42(9), 2095-2102

Kirtley, C. (2006). Clinical gait analysis: theory and practice. Elsevier Health Sciences Koga, H., Nakamae, A., Shima, Y., Iwasa, J., Myklebust, G., Engebretsen, L., Bahr, R., Krosshaug, T. (2010) Mechanisms for noncontact anterior cruciate ligament injuries: knee joint kinematics in 10 injury situations from female team handball and basketball. American Journal of Sports Medicine. 38(11), 2218-25 
Krosshaug, T., Nakamae, A., Boden, B., Engebretsen, L., Smith, G., Slauterbeck, J., \& Bahr, R. (2007). Mechanisms of anterior cruciate ligament injury in basketball video analysis of 39 cases. American Journal of Sports Medicine, 35(3), 359-367

Maykut, J., Taylor-Hass, J., Paterno, M., DiCesare, C., \& Ford, K. (2015). Concurrent validity and reliability of 2D kinematic analysis of frontal plane motion during running. International Journal of Sports Physical Therapy, 10(2), 136-146

McLean, S., Lipfert, S., \& van den Bogert, A. (2004). Effect of gender and defensive opponent on the biomechanics of sidestep cutting. Medicine and Science in Sports and Exercise, 36(6), 1008.

McLean, S., Walker, K., Ford, K., Myer, G., Hewett, T., \& van den Bogert, A. (2005). Evaluation of a two dimensional analysis method as a screening and evaluation tool for anterior cruciate ligament injury. British Journal of Sports Medicine, 39(6), 355-362

Mizner, R., Chmielewski, T., Toepke, J., \& Tofte, K. (2012). Comparison of Twodimensional Measurement Techniques for Predicting Knee Angle and Moment during a Drop Vertical Jump. Clinical Journal of Sport Medicine, 22(3), 221-226

Munro, A., Herrington, L., Carolan, M. (2012) Reliability of 2-Dimensional Video Assessment of Frontal-Plane Dynamic Knee Valgus During Common Athletic Screening Tasks. Journal of Sports Rehabilitation 21,7-11

Myer, G., Ford, K., Palumbo, O., \& Hewett, T. (2005). Neuromuscular training improves performance and lower-extremity biomechanics in female athletes. Journal of Strength \& Conditioning Research, 19(1), 51-60

Nagano, Y., Sakagami, M., Ida, H., Akai, M., \& Fukubayashi, T. (2008). Statistical modelling of knee valgus during a continuous jump test. Sports Biomechanics, 7(3), 342350 
Norris, B., \& Olson, S. (2011). Concurrent validity and reliability of two-dimensional video analysis of hip and knee joint motion during mechanical lifting. Physiotherapy Theory and Practice, 27(7), 521-530

Ortiz, A., Rosario-Canales, M., Rodríguez, A., Seda, A., Figueroa, C., \& Venegas-Ríos, H. (2016). Reliability and concurrent validity between two-dimensional and threedimensional evaluations of knee valgus during drop jumps. Open Access Journal of Sports Medicine, 7, 65-73

Paterno, M., Schmitt, L., Ford, K., Rauh, M., Myer, G., Huang, B., \& Hewett, T. (2010). Biomechanical measures during landing and postural stability predict second anterior cruciate ligament injury after anterior cruciate ligament reconstruction and return to sport. The American Journal of Sports Medicine, 38(10), 1968-1978

Schurr, S., Marshall, A., Resch, J., \& Saliba, S. (2017). Two-dimensional video analysis is comparable to 3D motion capture in lower extremity movement assessment. International Journal of Sports Physical Therapy, 12(2), 163-172

Shin, C., Chaudhari, A., \& Andriacchi, T. (2011). Valgus plus internal rotation moments increase anterior cruciate ligament strain more than either alone. Medicine and Science in Sports and Exercise, 43(8), 1484-1491

Shultz, S., Shimokochi, Y., Nguyen, A., Schmitz, R., Beynnon, B., \& Perrin, D. (2007). Measurement of varus-valgus and internal-external rotational knee laxities in vivo - Part II: relationship with anterior-posterior and general joint laxity in males and females. Journal of Orthopaedic Research, 25(8), 989-996

Sigward, S., Ota, S., \& Powers, C. (2008). Predictors of frontal plane knee excursion during a drop land in young female soccer players. Journal of Orthopaedic \& Sports Physical Therapy, 38(11), 661-667 
Sorenson, B., Kernozek, T., Willson, J., Ragan, R., \& Hove, J. (2015). Two-and Three Dimensional Relationships Between Knee and Hip Kinematic Motion Analysis: Single-Leg Drop Jump Landings. Journal of Sport Rehabilitation, 24(4), 363-372

Stensrud, S., Myklebust, G., Kristianslund, E., Bahr, R., \& Krosshaug, T. (2011). Correlation between two-dimensional video analysis and subjective assessment in evaluating knee control among elite female team handball players. British Journal of Sports Medicine, 45, 589-595

Willson, J., Binder-Macleod, S., \& Davis, I. (2008). Lower extremity jumping mechanics of female athletes with and without patellofemoral pain before and after exertion. The American Journal of Sports Medicine, 36(8), 1587-1596.

Willson, J., \& Davis, I. (2008). Utility of the frontal plane projection angle in females with patellofemoral pain. Journal of Orthopaedic \& Sports Physical Therapy, 38(10), 606-615 
Table 1: Participant demographics

\begin{tabular}{|c|c|c|c|c|}
\hline \multirow{4}{*}{$\begin{array}{l}\text { Ages } \\
\text { (years) }\end{array}$} & & Number & Mean (SD) & Range \\
\hline & Male & 19 & $28.6(4.5)$ & $20-35$ \\
\hline & Female & 15 & 26.8(2.9) & 24-31 \\
\hline & All & 34 & $28(3.9)$ & $20-35$ \\
\hline \multirow[t]{3}{*}{ Height (m) } & Male & 19 & $1.7(0.04)$ & $1.68-1.79$ \\
\hline & Female & 15 & $1.64(0.04)$ & $1.59-1.7$ \\
\hline & All & 34 & $1.7(0.05)$ & $1.59-1.79$ \\
\hline \multirow[t]{3}{*}{ Mass (kg) } & Male & 19 & $71(4.5)$ & $65-80$ \\
\hline & Female & 15 & $62.2(9.7)$ & $53-80$ \\
\hline & All & 34 & $67.7(7.9)$ & $53-80$ \\
\hline
\end{tabular}


Table 2: Testing procedure for each landing task

\begin{tabular}{|c|c|c|}
\hline Task & Instruction & Notes \\
\hline FSLL & $\begin{array}{l}\text { Participants were asked to stand on both legs } \\
\text { at the start point. } \\
\text { Then to jump forward and land on the right leg } \\
\text { in the middle of the force plate, keeping their } \\
\text { eyes open and focused forward, balance as fast } \\
\text { as possible, keep still as much as possible for } 5 \\
\text { seconds and then relax. Their arms were free } \\
\text { to move depending on participants' comfort. No } \\
\text { instructions were given about the landing } \\
\text { technique to avoid a coaching effect. } \\
\text { The same procedure was repeated for the left } \\
\text { leg }\end{array}$ & $\begin{array}{l}\text { The start point was } \\
\text { shown by tape placed } \\
\text { on the floor, in front and } \\
30 \mathrm{~cm} \text { away from the } \\
\text { centre of the force } \\
\text { platform }\end{array}$ \\
\hline LSLL & $\begin{array}{l}\text { The same procedure as FSLL but subjects were } \\
\text { asked to jump laterally from the start point and } \\
\text { land on the right leg. The same procedure was } \\
\text { repeated to land on the left leg but the force } \\
\text { platform and starting point were to the left of } \\
\text { the subject }\end{array}$ & $\begin{array}{l}\text { The starting point for } \\
\text { this test was shown by } \\
\text { tape placed on the floor, } \\
\text { beside and } 30 \mathrm{~cm} \text { away } \\
\text { from the centre of the } \\
\text { force plate. }\end{array}$ \\
\hline MSLL & $\begin{array}{l}\text { The same procedure as LSLL but the force plate } \\
\text { was on the left of the subjects, who jumped } \\
\text { towards the force plate and landed on their } \\
\text { right leg. The same procedure was repeated as } \\
\text { a mirror image for the left leg }\end{array}$ & $\begin{array}{l}\text { The starting point for } \\
\text { this test was shown by } \\
\text { tape placed on the floor, } \\
\text { beside and } 30 \mathrm{~cm} \text { away } \\
\text { from the centre of the } \\
\text { force plate. }\end{array}$ \\
\hline FSLLP & $\begin{array}{l}\text { The same procedure as FSLL but from a } \\
\text { platform }\end{array}$ & $\begin{array}{l}\text { Height of the platform is } \\
30 \mathrm{~cm} \text {. }\end{array}$ \\
\hline LSLLP & $\begin{array}{l}\text { The same procedure as LSLL but from a } \\
\text { platform }\end{array}$ & $\begin{array}{l}\text { Height of the platform is } \\
30 \mathrm{~cm} \text {. }\end{array}$ \\
\hline MSLLP & $\begin{array}{l}\text { The same procedure as MSLL but from a } \\
\text { platform }\end{array}$ & $\begin{array}{l}\text { Height of the platform is } \\
30 \mathrm{~cm} \text {. }\end{array}$ \\
\hline
\end{tabular}


Table 3: Means ( \pm SD) for 2D and 3D variables in all tasks

\begin{tabular}{|c|c|c|c|c|c|c|c|c|c|c|c|c|}
\hline & \multicolumn{12}{|c|}{ Task } \\
\hline Variable & \multicolumn{2}{|c|}{ FSLL } & \multicolumn{2}{|c|}{ FSLLP } & \multicolumn{2}{|c|}{ LSLL } & \multicolumn{2}{|c|}{ LSLLP } & \multicolumn{2}{|c|}{ MSLL } & \multicolumn{2}{|c|}{ MSLLP } \\
\hline & Right & Left & Right & Left & Right & Left & Right & Left & Right & Left & Right & Left \\
\hline \multicolumn{13}{|c|}{ 2D variables mean (SD) } \\
\hline FPPA & $\begin{array}{l}-7.9 \\
(4.8)\end{array}$ & $\begin{array}{l}-5.6 \\
(4.2)\end{array}$ & $\begin{array}{c}-8.3 \\
(5)\end{array}$ & $\begin{array}{c}-7.1 \\
(5.9)\end{array}$ & $\begin{array}{c}-5.8 \\
(3.6)\end{array}$ & $\begin{array}{l}-3.9 \\
(2.2)\end{array}$ & $\begin{array}{l}-6.3 \\
(3.5)\end{array}$ & $\begin{array}{c}-4.4 \\
(4.4)\end{array}$ & $\begin{array}{l}-9.7 \\
(6.4)\end{array}$ & $\begin{array}{c}-6.9 \\
(5.5)\end{array}$ & $\begin{array}{r}-12.4 \\
(8.4) \\
\end{array}$ & $\begin{array}{c}-9.3 \\
(6.3)\end{array}$ \\
\hline HADD & $\begin{array}{c}7.6 \\
(4.7)\end{array}$ & $\begin{array}{c}6.7 \\
(4.5)\end{array}$ & $\begin{array}{c}7.3 \\
(5.1)\end{array}$ & $\begin{array}{c}7.5 \\
(5.7)\end{array}$ & $\begin{array}{c}3.6 \\
(4.7)\end{array}$ & $\begin{array}{c}4.3 \\
(2.2)\end{array}$ & $\begin{array}{c}4.8 \\
(4.9)\end{array}$ & $\begin{array}{c}4.5 \\
(4.9)\end{array}$ & $\begin{array}{l}7.7 \\
(5)\end{array}$ & $\begin{array}{c}5.5 \\
(5.7)\end{array}$ & $\begin{array}{c}9.6 \\
(4.4)\end{array}$ & $\begin{array}{c}7.1 \\
(5.5)\end{array}$ \\
\hline \multicolumn{13}{|c|}{ 3D variables mean (SD) } \\
\hline Knee valgus & $\begin{array}{l}-1.3 \\
(3.9)\end{array}$ & $-6(3.9)$ & $\begin{array}{l}-1.8 \\
(4.2)\end{array}$ & $\begin{array}{l}-1.3 \\
(3.7)\end{array}$ & $\begin{array}{l}-3.4 \\
(3.3)\end{array}$ & $\begin{array}{c}-2.4 \\
(3.5)\end{array}$ & $\begin{array}{l}-2.8 \\
(3.6)\end{array}$ & $\begin{array}{c}-2.1 \\
(3.7)\end{array}$ & $\begin{array}{c}-2 \\
(5.1)\end{array}$ & $\begin{array}{c}-1 \\
(3.5)\end{array}$ & $\begin{array}{l}-3.1 \\
(5.5)\end{array}$ & $\begin{array}{c}-2.3 \\
(4.2)\end{array}$ \\
\hline HADD & $\begin{array}{c}6.5 \\
(4.9) \\
\end{array}$ & $\begin{array}{c}5.8 \\
(5.4) \\
\end{array}$ & $\begin{array}{c}7.6 \\
(6.3) \\
\end{array}$ & $\begin{array}{c}6.6 \\
(5.6) \\
\end{array}$ & $\begin{array}{c}3.8 \\
(6.2) \\
\end{array}$ & $\begin{array}{c}5.1 \\
(4.9) \\
\end{array}$ & $\begin{array}{c}4.6 \\
(6.4) \\
\end{array}$ & $\begin{array}{c}5.3 \\
(5.8) \\
\end{array}$ & $\begin{array}{c}7.1 \\
(5.6) \\
\end{array}$ & $\begin{array}{c}6.7 \\
(6.6) \\
\end{array}$ & $\begin{array}{c}8.8 \\
(5.3) \\
\end{array}$ & $\begin{array}{r}7.2 \\
(6.2) \\
\end{array}$ \\
\hline
\end{tabular}

All values are in degrees, FSLL $=$ forward single-leg landing, FSLLP $=$ forward single-leg landing off a platform, LSLL $=$ lateral single leg landing, LSLLP = lateral single-leg landing off a platform, MSLL = medial single-leg landing, MSLLP = medial single-leg landing off a platform, HADD = hip adduction angle, $\mathrm{RT}=$ right leg, $\mathrm{LT}=$ left leg, $2 \mathrm{D}=$ two-dimensional, $3 \mathrm{D}=$ three-dimensional, $\mathrm{SD}=\mathrm{standard}$ deviation. 
Table 4: Pearson correlation $(r)$ [95\% confidence interval] ( $P$ values), and linear regression analysis ( $r^{2}$ ) for $2 D$ variables with 3D variables for both legs during all tasks

\begin{tabular}{|c|c|c|c|c|c|c|c|c|c|c|c|c|}
\hline & \multicolumn{2}{|c|}{ FSLL } & \multicolumn{2}{|c|}{ LSLL } & \multicolumn{2}{|c|}{ MSLL } & \multicolumn{2}{|c|}{ FSLLP } & \multicolumn{2}{|c|}{ LSLLP } & \multicolumn{2}{|c|}{ MSLLP } \\
\hline Variable & Right & Left & Right & Left & Right & Left & Right & Left & Right & Left & Right & Left \\
\hline FPPA & & & & & & D knee ve & gus angle & & & & & \\
\hline$r(p)$ & $\begin{array}{c}0.42 \\
{[.12-.72]} \\
(0.01)\end{array}$ & $\begin{array}{c}0.35 \\
{[.1-.68]} \\
(0.04)\end{array}$ & $\begin{array}{c}0.28 \\
{[.17-.64]} \\
(0.11)\end{array}$ & $\begin{array}{c}0.4 \\
{[.1-.71]} \\
(0.02)\end{array}$ & $\begin{array}{c}0.2 \\
{[.05-.58]} \\
(0.24)\end{array}$ & $\begin{array}{c}0.37 \\
{[.07-.69]} \\
(0.03)\end{array}$ & $\begin{array}{c}0.26 \\
{[.06-.62]} \\
(0.13)\end{array}$ & $\begin{array}{c}0.17 \\
{[.02-.56]} \\
(0.33)\end{array}$ & $\begin{array}{c}0.18 \\
{[.02-.57]} \\
(0.31)\end{array}$ & $\begin{array}{c}0.26 \\
{[.06-.62]} \\
(0.14)\end{array}$ & $\begin{array}{c}0.02 \\
{[.05-.58]} \\
(0.92)\end{array}$ & $\begin{array}{c}0.29 \\
{[.1-.64]} \\
(0.09)\end{array}$ \\
\hline$r^{2}$ & 0.17 & 0.12 & 0.08 & 0.16 & 0.04 & 0.14 & 0.07 & 0.03 & 0.03 & 0.07 & 0.004 & 0.08 \\
\hline $\begin{array}{l}\text { 2D } \\
\text { HADD }\end{array}$ & & & & & & 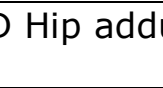 & inn anal & & & & & \\
\hline$r(p)$ & $\begin{array}{c}0.79 \\
{[.54-.91]} \\
(0.01)\end{array}$ & $\begin{array}{c}0.7 \\
{[.38-.87]} \\
(0.001)\end{array}$ & $\begin{array}{c}0.81 \\
{[.58-.92]} \\
(0.001)\end{array}$ & $\begin{array}{c}0.72 \\
{[.42-.88]} \\
(0.001)\end{array}$ & $\begin{array}{c}0.9 \\
{[.77-.96]} \\
(0.001)\end{array}$ & $\begin{array}{c}0.88 \\
{[.72-.95]} \\
(0.001)\end{array}$ & $\begin{array}{c}0.85 \\
{[.66-.94]} \\
(0.001)\end{array}$ & $\begin{array}{c}0.85 \\
{[.66-.94]} \\
(0.001)\end{array}$ & $\begin{array}{c}0.79 \\
{[.54-.91]} \\
(0.001)\end{array}$ & $\begin{array}{c}0.88 \\
{[.72-.95]} \\
(0.001)\end{array}$ & $\begin{array}{c}0.72 \\
{[.42-.88]} \\
(0.001)\end{array}$ & $\begin{array}{c}0.84 \\
{[.64-.93]} \\
(0.001)\end{array}$ \\
\hline$r^{2}$ & 0.62 & 0.49 & 0.66 & 0.52 & 0.81 & 0.77 & 0.72 & 0.72 & 0.62 & 0.77 & 0.59 & 0.71 \\
\hline
\end{tabular}

$2 \mathrm{D}=$ two-dimensional, 3D = three-dimensional, FSLL = forward single-leg landing, FSLLP = forward single-leg landing off a platform, LSLL $=$ lateral single-leg landing, LSLLP = lateral single-leg landing off a platform, MSLL = medial single-leg landing, MSLLP = medial single leglanding off a platform, FPPA, frontal plane projection angle, HADD = hip adduction angle. 